\title{
Cognitive Factors Influencing the Environmental Practices of Students: Implication for Environmental Education
}

\author{
Norris Igbinosa Erhabor ${ }^{1 *}$, Victor Braimoh ${ }^{1}$
}

${ }^{1}$ University of Benin, NIGERIA

*Corresponding Author: norris.erhabor@uniben.edu

Citation: Erhabor, N. I., \& Braimoh, V. (2020). Cognitive Factors Influencing the Environmental Practices of Students: Implication for Environmental Education. Aquademia, 4(1), ep20013. https://doi.org/10.29333/aquademia/8224

\section{ARTICLE INFO}

Received: 28 Apr. 2020

Accepted: 30 Apr. 2020

\begin{abstract}
The purpose of the study was to determine the influence of cognitive factors (knowledge and attitudes) on the practice of students towards the environment. In the study four research questions were raised and one was hypothesized. A quantitative research with descriptive approach was utilized in the study. The population of the study comprised of 15,116 students in senior secondary schools two in Benin metropolis, Nigeria (private, state and Federal Government owned secondary schools). The sample size for the study was 255 students selected using multi-stage sampling technique. The techniques used were clusters, convenience and systematic random sampling techniques. The instrument for the study was a modified questionnaire with standard items that has been used for previous student environmental related studies. It was discovered in the study that majority of the respondents had low knowledge of waste disposal, wildlife conservation and green energy but they had high knowledge toward pollution control. It was also seen that most of the respondents had positive attitude towards the environment but indicated that they engage in unfriendly environmental practices. However, a hierarchical multiple regression revealed that the respondents knowledge and attitude did not significantly predict their environmental practices. Based on the low knowledge and poor environmental practices of the respondents, it was recommended that environmental education should be given priority in Nigeria educational system because without an environmentally smarter next generation policy makers, entrepreneurs and consumers, environmentally sustainable practices will be obsolete or given little priority.
\end{abstract}

Keywords: cognitive factors, environmental practice, environmental education, Nigeria

\section{INTRODUCTION}

Anijah, Eneji and Ubom (2013) observed that the global interests about the predicament of the environment, especially in the face of prevailing mass poverty, disease, filth, malnutrition, hunger, population growth, unemployment and pollution of air, land and water, has made it compelling for most countries to improve the understanding, attitude and practice (environmental literacy) of their citizen as a precondition for environmental quality. Thus, it is believed that environmental education (EE) will most likely improve public awareness, engender eco-friendly attitudes and develop management skills and strategies that will minimize environmental damage.

Environmental Education is of paramount importance in the $21^{\text {st }}$ century in sensitizing individuals on the need to adopt attitudes and practices that show respect for the environment. In a more encompassing definition Jia-nan (2012) defines Environmental Education (EE) as organized efforts to teach how natural environments function and particularly, how human beings can manage their behaviors and protect the ecosystems for sustainability. Environmental Education was born out of the realization that solving complex local and global problems cannot be accomplished by politicians and experts alone, but requires "the support and active participation of an enlightened public in their various functions as employers, voters, consumers, and leaders in both community and business." (Kyburz-Graber, Hofer, \& Wolfensberger, 2006). It finds her formal root in the United Nations Conference on the Human environment in Stockholm of 1972. This conference recommended establishment of an International Environmental Education Programme. IEEP was launched in 1975. It recommended the primary categories of environmental education curriculum goals and objectives comprising awareness, attitudes, skills and participation, which of course stands to be relevant to this study (United Nations Educational and Cultural Organization, UNESCO, 1999). From the foregoing it is imperative to understand that for school children to meaningfully participate in proenvironmental or environment friendly activities, they require awareness, knowledge and skills gained through EE. These 
qualities are personal thought, feeling and action which develop in the students through an educational process that creates awareness, develops attitude and builds capacity and willingness to take action as an individual and as a group (Toili, 2007). It must be noted that developing positive attitude towards the environment is one of the goal of EE and is of great importance to students who will eventually go all out in ensuring safe and quality environment, when they are in positions to make policies as regarding the environment, besides they can through the knowledge of environmental education adopt alternate source of energy which will reduce the incidence of pollution and destruction heightened by other unsustainable and dated methods. Braimoh (2015) noted for example that positive attitude towards solid waste disposal can be nurtured and developed from a young age leading to positive changes in behavior and the general disposition towards solid wastes as a result of sound environmental education.

In primary and secondary schools in Nigeria, relevant curriculum content such as environmental pollution, environmental hazards, natural and human resources management, land degradation, climate change, sanitation, effects of industrial concentration, green house gases, weather and climate, classification of climate among others are infused into curriculum in subjects like chemistry, physics, biology, geography, agriculture and social Studies. Thus, environmental education content is infused into other subjects in the country. These subjects are meant to promote students' knowledge towards their environment and at the same time develop in students the environmental friendly attitude that will enable them live and interact with their environment in a friendly manner. Various comments have been made about the role of EE in encouraging safer and environmentally friendly schools but how much has it been functional in terms of practice towards ensuring a safe and protected environment. For instance, the researchers observed that these students in Nigeria still display environmental unfriendly behaviours such as indiscriminately dump their used plastics, cans, sachet water on the environment; leave taps running; papers are also wasted which could have been reused; forget to switch off appliances in their classrooms like light bulbs, fans, air conditioners, electrical switch used for practical; lack of concern for environmental friendly events amongst other activities. In view of this trend, the achievement of an environmental friendly future in this part of the world is doubtful. Thus, the need in assess the various internal characteristics of students (cognitive factors) that affects their environment practice. In this study knowledge and attitude was chosen as the cognitive factors to explain the environmental practice of students. Therefore, this study became imperative as the researchers sought to ascertain the environmental knowledge, environmental attitudes, environmental practices and finally how the cognitive factors (environmental knowledge and attitude) influence the environmental practice of secondary students.

\section{Research Questions}

The following research questions were raised for the study:

1. What is the level of knowledge of selected environmental concepts among secondary students?
2. What are the environmental attitudes of secondary school students?

3. What is the level of practice of students towards the environment?

4. Do the cognitive factors (environmental knowledge and attitude) predict the environmental practices of secondary school students?

\section{Research Hypothesis}

One research hypothesis was raised to guide this study.

1. Cognitive factors (environmental knowledge and attitude) do not significantly predict the environmental practices of secondary school students?

\section{Purpose of the Study}

The main purpose of the study was to determine the influence of environmental knowledge, and attitudes on the environmental practices of students in Edo State, Nigeria.

\section{METHOD OF THE STUDY}

This study employed the quantitative research with descriptive approach. The population of the study comprised of all students in senior secondary schools two in Benin metropolis (private, state and Federal Government owned secondary schools). According to the Edo State Ministry of Education, there are 15, 118 students from senior secondary school two in Benin metropolis. The sample size for the study was 255 students selected using multi-stage sampling technique. It involved clusters of existing secondary schools to comprise private, state and federal owned secondary schools. The researchers then used convenience sampling to select appropriate number of private and public schools (Federal Government College) included. Thereafter, the researchers adopted systematic random sampling making use of the register of the class to select the respondents that was used for the study. The instrument for the study will be a modified questionnaire with standard items that has been used for previous student environmental related studies (Kaul, 2004; de Groot \& Steg, 2007; Digby, 2012; Singha, 2013). The internal consistency of the instrument was derived to ascertain the reliability of the instrument. The scores obtained from the respondents were correlated using Cronbach Alpha Coefficient. The correlation coefficients obtained were 0.83 for the knowledge scale, 0.89 for the attitude scale and 0.81 for the practice scale. This proofs that the instrument is reliable. The instrument for this study was a questionnaire made up of various sections. Section A had separate demographic data for students which include age, type of class, gender, location of residence and Parental Educational Qualification. The section B comprised of twenty multiple choice questions on environmental knowledge, which were divided into four concepts. Each concept had five questions. Section C comprised of ten environmental attitudes items while section $\mathrm{D}$ was composed of ten environmental practice items. The attitude was sought by using the Modified Likert Scale format of Strongly Agree (4), Agree (3), Disagree (2) and Strongly Disagree (1). In the case of practice, the researchers used the scale "Always (3)", "sometimes (2)" and "Never (1)" to indicate 
Table 1a. Students level of environmental knowledge of selected concepts

\begin{tabular}{cccc}
\hline Concepts & Categories & Frequency & Percent \\
\hline Waste disposal & Low knowledge & 160 & 62.7 \\
& High knowledge & 95 & 37.3 \\
& & $\mathbf{2 5 5}$ & 100 \\
\hline Pollution & Low knowledge & 67 & 26.3 \\
control & High knowledge & 188 & 73.7 \\
& & $\mathbf{2 5 5}$ & $\mathbf{1 0 0}$ \\
\hline Wildlife & Low knowledge & 163 & 64.0 \\
conservation & High knowledge & 92 & 36.0 \\
& & $\mathbf{2 5 5}$ & $\mathbf{1 0 0}$ \\
\hline Green energy & Low knowledge & 143 & 56.1 \\
& High knowledge & 112 & 43.9 \\
& & $2 \mathbf{5 5}$ & $\mathbf{1 0 0}$ \\
\hline
\end{tabular}

practice levels. The negatively worded items were coded in reverse option.

\section{Scoring}

Environmental knowledge: There were twenty multiple choice questions specifically on select environmental concepts (waste disposal, pollution control, wildlife conservation and energy). Correct answer for each item had score of one (1) while incorrect answer had score of zero (0). Each concept was scored differently and categorized accordingly

Low knowledge: 0-2 0-10 (overall low knowledge)

High Knowledge: 3-5 11-20 (overall high knowledge)

Attitudes toward Environment: For the attitude questions, using the Likert scale format, the respondents with positive attitude had score of 21 to 40 while negative attitude had score of 1 to 20 .

Environmental Practice: The respondents were categorized into: Environmental unfriendly practice (low practices): score of 1-14; Environmental friendly practice (high practices): score of $15-30$.

\section{Ethical Consideration}

The instrument was administered by the researcher with the aid of trained research assistants. The instrument was administered after permission was obtained from the appropriate Ministry of Education and a written letter of introduction to the principal and then the sample obtained was used for the study.

\section{RESULTS}

Research Question 1: What is the Level of Knowledge of Selected Environmental Concepts among Secondary Students?

Table 1a reveals the environmental knowledge of the students on selected environmental concepts. From the table above, it can be deduced that majority of the respondents $62.7 \%$ lack proper knowledge of waste disposal but $73.7 \%$ of the students have high knowledge of the concept of pollution. This is an environmental concept that student are knowledgeable about. In terms of the concept of wildlife conservation, the data above showed that $64 \%$ of the students have low knowledge. Conservation is needed in ensuring
Table 1b. Overall students level of environmental knowledge of selected concepts

\begin{tabular}{ccc}
\hline Knowledge & Frequency & Percentage \\
\hline High & 93 & 36.5 \\
\hline Low & 162 & 63.5 \\
\hline Total & $\mathbf{2 5 5}$ & $\mathbf{1 0 0}$ \\
\hline
\end{tabular}

Table 2. Environmental Attitudes of students

\begin{tabular}{ccc}
\hline Attitude & Frequency & Percentage \\
\hline Positive & 174 & 68.2 \\
\hline Negative & 81 & 31.8 \\
\hline Total & $\mathbf{2 5 5}$ & $\mathbf{1 0 0}$
\end{tabular}

Table 3. Practice level of students to environmental protection and sustainability

\begin{tabular}{ccc}
\hline Practice level & N & \% \\
\hline Low practice & 210 & 82.4 \\
\hline High practice & 45 & 17.6 \\
\hline Total & $\mathbf{2 5 5}$ & $\mathbf{1 0 0}$ \\
\hline
\end{tabular}

environmental sustainability and achieving the goals of Environmental Education. This could mean that the teaching method of the teachers in environmental Education is not holistic as it may only affect the cognitive domain, neglecting the psychomotor and affective domain. The study also revealed that the students know little concerning emergent environmental concepts like green energy, $56.1 \%$ of the students had low knowledge of the concept of green energy. This is of vital significance as unavailability of knowledge as regards issues that are emerging and current, will not prepare the students adequately for developing sustainability goals of environmental protection and conservation.

Table $1 \mathrm{~b}$ reveals the general knowledge of the respondents towards the environment. It can be deduced that majority of the respondents have low level of knowledge (63.5\%) towards the environment while $36.5 \%$ have high knowledge.

Research Question 2: What are the Environmental Attitudes of Secondary School Students?

From Table 2, 68.2\% $(\mathrm{n}=174)$ of the respondent showed a positive environmental attitude while $31.8 \%(n=81)$ showed a negative attitude towards the environment. This was really surprising for the researchers as majority of the respondents had poor knowledge of the environment but have positive attitude towards the environment.

\section{Research Question 3: What is the Level of Practice of Students towards the Environment?}

From Table 3, 82.4\% ( $\mathrm{n}=210)$ of the respondents indicated that they had low environmental practice (engage in unfriendly environmental practices) while $17.6 \%(\mathrm{n}=45)$ showed a high practice (engage in friendly environmental practices). This shows that most of the students engage in anti-environmental activities (environmental unfriendly practices). 
Table 4. Correlation matrix of criterion and predictor variables

\begin{tabular}{|c|c|c|c|c|}
\hline & & Practice & Know & Attitude \\
\hline \multirow{3}{*}{ Pearson Correlation } & Practice & 1.000 & .089 & .099 \\
\hline & Know & .089 & 1.000 & .110 \\
\hline & Attitude & .099 & .110 & 1.000 \\
\hline \multirow{3}{*}{ Sig. (1-tailed) } & Practice &. & .079 & .058 \\
\hline & Know & .079 & . & .040 \\
\hline & Attitude & .058 & .040 &. \\
\hline
\end{tabular}

Table 5. Summary of hierarchical regression analysis for cognitive factors predicting environmental practice

\begin{tabular}{cccccccc}
\hline Variable & $\mathbf{B}$ & $\mathbf{F}$ & $\mathbf{t}$ & Std. error & $\mathbf{R}$ & $\mathbf{R}^{2}$ & 0.008 \\
\hline Stage 1 & & 2.005 & & & 0.089 & 0.008 \\
Know & 0.089 & & 1.416 & 3.871 & & 0.020 & 0.012 \\
\hline Stage 2 & & 2.539 & & & & & \\
Know & 0.101 & & 1.606 & 3.851 & & \\
Attitude & 0.110 & & 1.849 & 3.472 & & \\
\hline
\end{tabular}

$\mathrm{N}=255 * \mathrm{p}<0.05$

Research Question 4: Do the Cognitive Factors (Environmental Knowledge and Attitude) Predict the Environmental Practices of Secondary School Students?

From Table 4, it shows the Pearson Correlation of the variables of the study. It can be deduced that the correlation between practice and attitude is not significant, weak, positive relationship ( $r=0.099, \mathrm{p}>0.05)$, while the correlation between practice and knowledge is also not significant, weak, positive relationship ( $\mathrm{r}=0.089, \mathrm{p}>0.05)$. However, a significant, weak, positive relationship is observed between attitude and knowledge in the study $(\mathrm{r}=0.110, \mathrm{p}<0.05)$.

\section{Hypothesis Testing}

Cognitive factors (environmental knowledge and attitude) do not predict the environmental practices of secondary school students

However, before using hierarchical multiple regression, the relevant assumptions of this statistical analysis were tested. A sample size of 255 is adequate given two independent variables. The assumption of singularity was also met. Thereafter an examination of correlation, it was deduced that no independent variables were highly correlated and the collinearity statistics (tolerance and VIF) were all within accepted limits. Hence assumption of multicollinearity was met.

The table revealed from the hierarchical multiple regression that at stage one, knowledge did not contribute significantly to the regression model, $\mathrm{t}=1.416, \mathrm{p}>0.05$ and accounted for $0.8 \%$ of the variation in the environmental practice of the students. Meanwhile in stage two, both knowledge and environment attitude together predicted additional $2 \%$ of the variation in environmental practice and this change in $\mathrm{R}^{2}$ was not significant, $\mathrm{F}(1,253)=2.539$, $\mathrm{p}>0.05$. However environmental attitude alone only contributed $1.2 \%$ to the model in explaining the variation in environmental practice and its contribution can be seen as not significant as $t=1.749, p>0.05$. Furthermore, knowledge had no significant positive regression weight $(B=0.089, \quad p>0.05)$ while environmental attitude had no significant positive weight $(\mathrm{B}=0.055, \mathrm{p}>0.05)$. This result reveals that attitude and knowledge did not significantly contribute to the multiple regression model. Hence the null hypothesis which states that cognitive factors (environmental knowledge and attitude) do not predict the environmental practices of secondary school students is accepted. This means that in the study both their environmental knowledge and attitude does not significantly predict the students' environmental practice. This is another exceptional finding in this study.

\section{DISCUSSION OF FINDINGS}

The environmental knowledge of students was the first objective of the study. The study revealed that the level of knowledge when categorized differed from one environmental concept to another. For instance, the students had low knowledge of waste recycling, wildlife conservation and green energy. Meanwhile, it was found out that the level of knowledge for pollution was high. A good number of students had full understanding of the concept of pollution. But generally, majority of the respondents had low knowledge of the environment in the study. This is inline with result of the result of the Ernesto (2004) study which revealed that there was a vehement misinformation among the populace and many who thought they know about the environment were erroneous about the facts. Hence Shobeiri (2005) stated that solving existing environmental challenges needs environmental awareness and its proper understanding which should be deeply rooted in the education system at all levels of school education.

The second objective of the study was to find out the environmental attitudes of the students of Benin Metropolis. The study revealed that their attitude was positive. This large number of respondents with positive attitude towards the forest is in line with the study by Bengston and Fan (1999) when they observed that the majority of respondents in their study held positive attitudes about roads in national forests where they provide recreational access. As far as students will wish to see protected and well taken care of environment, they will prefer other people to do the work and not themselves, which might be the reason for the positive attitude towards the environment. Regarding practice, the respondents generally showed a low practice of sound environmental practice that is they engage in unfriendly practice. They respondent that 
dumping waste in drainages, road paths and so on was normal; exhibited improper practice to conserve and protect the environment amongst others. This anti-environmental practices indicated by the respondents substantiated the observations of the researchers. This contrary to the study by Digby (2010) which revealed pro-environmental behavior among Minnesota adults was mixed with some reporting they engaged in participating in some pro-environmental behaviors and not in others. While study of Gatersleben, Steg and Vlek (2002) showed that pro-environmental behavior is more strongly related to attitudinal variable.

The result from the pearson correlation revealed that there were not significant, weak and positive relationship between environmental practice and environmental attitude. Also same weak positive relationships were observed between knowledge and environmental practice but a significant positive relationship was observed between environmental attitude and environmental knowledge. These are contrary with the study by report by Kaiser, Ranney, Hartig and Bowler (1999) revealed a positive correlation between environmental attitude and environmental behaviors. Studies by Eilam and Trop (2010) revealed that the respondents' posses' positive attitude towards the environment but the strategies required for influencing attitudes are different from those required for influencing behavior.

In the hierarchical multiple regression to ascertain the how the cognitive factors (environmental knowledge and environmental attitude) predicts environmental practice of the students. It was observed from the multiple regression that a combination of environmental knowledge and environmental attitude did not significantly predict the environmental practice of the students. That is the two independent variables (knowledge and environmental attitude) explained $2 \%$ of the variation in the dependent variable (environmental practice). But only the knowledge variable explained $0.8 \%$ of the variance in the students' environmental practice while environmental attitudes alone explained $1.2 \%$ of the variance of the respondents practice. Hence both variables are seen as weak predictors of the students' environmental practice. Thus the null hypothesis which stated that cognitive factors did not significantly predict environmental practice was accepted. This shows that the cognitive factors do not significantly influence the low level of environmental practices (unfriendly environmental practice) of the students as the factors only explained $2 \%$ of the variance of practice.

\section{CONCLUSION}

In conclusion, the study also revealed that there is no significant relationship between the environmental knowledge and environmental attitude on the unfriendly environmental practices the respondents engages. That is knowledge and attitude does not necessarily translate into environmental practices. The study also made some striking observations that despite the low knowledge of the respondents, majority of them indicated that they possess positive attitude towards the environment. Both exceptional findings of this study are contrary to several reports, hence the need for further studies.

\section{RECOMMENDATIONS}

Following the findings of the study, the following recommendations are made to ensure that the objectives of the study are met.

1. In the aspect of the low knowledge and poor environmental practices, environmental education should be given priority in Nigeria educational system because without an environmentally smarter next generation policy makers, entrepreneurs and consumers, environmentally sustainable practices will be obsolete or given little priority.

2. There is need to review the current method of teaching environmental education in schools. Due to the findings of the study, environmental education should be taught as a separate subject in both primary and secondary school.

3. Based on the present method (integrated into other subjects) of teaching environmental education in Nigeria, retraining and training of teachers on the concept of environmental education should be organized by education stakeholder. But experts in environmental education should be utilized as resource persons.

4. More should be done to celebrate the environment in school; programs like earth day, keeping the environment clean should be taken with utmost concern and seriousness. The essence should not be to acquire knowledge regarding the environment, but rather efforts should be made especially from staff to show and practice responsible environmental behavior.

5. Competitions by various schools should be done relating to environmental protection and preservation, these competitions should focus on external environmental project, not just orals and the government should ensure that the students are adequately rewarded.

6. Governments and local school authorities could make use of the rewarding social media platform to show case environmental related projects which will go a long way in encouraging sound environmental practice that will engender the need to project the earth and not just be aware of the various environmental problems without proffering any solution.

7. Opportunities should be given to staff and students to actively represent the state in environment summit locally and internationally, and this should be effectively showcased on television and radio channels which will boost the interest and commitment of other students and staff. 


\section{IMPLICATION FOR ENVIRONMENTAL EDUCATION}

Education provides the avenue to address human resource limitations and to raise understanding of the environment in the general public. Based on the low level of knowledge and poor environmental practices of the respondents, there is an urgent need to improve education in general and thus the public awareness in relation to the environment. Environmental Education should be made priority in protecting the environment and its resources especially with the long time scale over which national-level changes in the environment occurs. Also with the country population skewed towards younger generation, education for the environment (environmental education) should be fully implemented in the various educational sectors because without an environmentally smarter next generation policy makers, entrepreneurs and consumers, environmentally sustainable practices will be obsolete or given little priority. Thus making resources irretrievably eroded.

\section{REFERENCES}

Anijah, O. F., Eneji, V. O., \& Ubom, A. E. (2013). Environmental Education for Public Awareness: The role of educational administrators and planners. International journal of Sociology and Anthropology, 5(1), 12 -17. https://doi.org/ 10.5897/IJSA12.049

Braimoh, V. C. (2015). Knowledge, Attitudes and Practices of Solid Waste Management among students of the University of Benin (Unpublished M.Ed. Thesis), Department of Health Safety and Environmental Education. University of Benin, Benin City.

De groot, J., \& Steg, L. (2005). General beliefs and the theory of planned behavior: the role of environmental concerns in the TPB. Journal of Applied Social Psychology, 37(8) 18171836. https://doi.org/10.1111/j.1559-1816.2007.00239.x

Digby, C. L. (2010). An examination of the impact of non-formal and informal learning on adult environmental knowledge, attitudes, and behaviors (Unpublished EdD Dissertation). Minnesota: The University of Minnesota.

Eilam, E., \& Trop, T. (2010). Environmental attitudes and environmental behavior-which is the horse and which is the cart. Sustainability, 4, 2210-2246. https://doi.org/ $10.3390 /$ su4092210
Ernesto, D. L. (2004). Awareness, knowledge, and attitude about environmental education: responses from environmental specialists, high school instructors, students, and parents (Unpublished Ph.D Dissertation). Florida: University of Central Florida- Orlando.

Gatersleben, B., Steg, L., \& Vlek, C. (2002). Measurement and determinants of environmentally significant consumer behavior. Environment and Behavior, 34, 335-362. https://doi.org/10.1177/0013916502034003004

Ishaya, S. I., \& Abaje, I. B. (2008). Indigenous people's perception on climate change and adaptation strategies in Jema, a local government area of Kaduna state, Nigeria. Journal of Geography and Regional Planning, 1(8), 138-143. Retrieved from http://www.academic-journals.org/JGRP

Jia-nan, C. (2012). Contributions of Environmental NGO to Environmental Education in China. 2012 International Conference on Future Computer Supported Education. SciVerse ScienceDirect IERI Procedia, 2(2012), 901-906. https://doi.org/10.1016/j.ieri.2012.06.189

Kaiser, F. G., Ranney, M., Hartig, T., \& Bowler, P. A. (1999). Ecological behavior, environmental attitude, and feelings of responsibility for the environment. European psychologist, 4, 59-74. https://doi.org/10.1027//10169040.4.2.59

Kaul, O. N. (2004). Impact knowledge - attitude - practice of staff training in Haryana community forestry project. Haryana Community Forestry Project, Panchkula.

Kyburz-Graber, R., Hofer, K., \& Wolfensberger, B. (2006). Studies on a socio-ecological approach to environmental education - a contribution to a critical position in the education for sustainable development discourse. Environmental Education Research, 12(1), 101-114. https://doi.org/10.1080/13504620500527840

Shobeiri, S. (2005). A Comparative Study of Environmental Awareness and Attitude of Teachers and Students of Secondary Schools in India and Iran ( $\mathrm{PhD}$ Thesis). Department of Education, University of Mysore, India.

Singha, A. K. (2013). Assessing forest villager' role perception and role performance behavior towards social development with forest resources in Assam. Journal Humanistic Ecology, 41(1), 77-82. https://doi.org/10.1080/09709274.2013. 11906555

Toili, W. W. (2007). Secondary School Students' Participation in Environmental Action: Coercion or Dynamism? Eurasia Journal of Mathematics, Science \& Technology Education, 3(1), 51-69. https://doi.org/10.12973/ejmste/75374

UNESCO (1999). Environmental Education and Training in Egypt, UNESCO, Paris. 